\title{
Effect of high loading of titanium dioxide particles on the morphology, mechanical and thermo-mechanical properties of the natural rubber-based composites
}

\author{
Janusz Datta ${ }^{1}$ (D) Paulina Kosiorek ${ }^{1} \cdot$ Marcin Włoch $^{1}$
}

Received: 5 May 2016 / Accepted: 1 November 2016 / Published online: 7 November 2016

(C) The Author(s) 2016. This article is published with open access at Springerlink.com

\begin{abstract}
The aim of this work was to prepare and characterize the natural rubber vulcanizates containing different amounts of titanium dioxide particles. At first, a rubber mixture was prepared using a laboratory two-roll mill and then samples were vulcanized by a hydraulic press. The formulation of the rubber mixture and rubber-processing technique were based on our earlier investigations. Samples were obtained with different titanium dioxide loadings of $15,25,45$, and 85 parts by weight per hundred parts of natural rubber. This research is focused on the determination of the influence of different loadings of titanium oxide particles on the chemical structure, morphology, mechanical and thermo-mechanical properties of the natural rubberbased composites. It was found that vulcanizates with different amounts of $\mathrm{TiO}_{2}$ particles possess good characteristic in terms of all measured properties. The results of Fourier transform infrared spectroscopy analysis showed that the chemical structure of the obtained natural-based composites was not influenced by titanium dioxide particles. The SEM micrographs showed the uniform dispersion of $\mathrm{TiO}_{2}$ particles in the natural rubber matrix. The agglomeration of filler was seen at the higher contents of $\mathrm{TiO}_{2}$ in the matrix. The thermogravimetric analysis showed slightly different thermal stability for the obtained natural rubber composites. The dynamic mechanical thermal analysis showed that the prepared materials have similar glass transition temperatures. However, increase in the content of titanium dioxide in the obtained materials is connected with higher energy
\end{abstract}

Janusz Datta

janusz.datta@pg.gda.pl

1 Department of Polymers Technology, Faculty of Chemistry, Gdańsk University of Technology, G. Narutowicza Str. 11/12, 80-233 Gdansk, Poland loss (higher dissipation of energy) during the mechanical work of material and higher cross-link density of the prepared materials.

Keywords Natural rubber composites - Titanium dioxide · Mechanical properties · Dynamic mechanical properties · Thermal stability $\cdot$ Swelling properties

\section{Introduction}

Natural or synthetic rubber-based composites with inorganic fillers possess increasing importance from the technological point of view $[1,2]$. The practical applications are determined by achievement of desirable mechanical and dynamic properties of rubber-based materials, which is connected with the optimal degree of cross-linking in the rubber vulcanizates. The cross-link density should be high enough to prevent viscous flow, but low to avoid brittle failure of the vulcanizates materials [3]. Rubber materials are commonly used for the production of o-rings, seals, tires or conveyor belts [4].

There are many kinds of rubbers, such as butadiene rubber (BR), ethylene-propylene-diene monomer rubber (EPDM), nitrile-butadiene rubber (NBR) [5], styrene-butadiene rubber (SBR), and natural rubber (NR) [5-8]. Natural rubber shows sufficient tensile strength; tear strength and abrasion resistance for many applications [4, 8]. On the other hand, NR is an unsaturated polymer, sensitive to oxidation initiated by heat, ultraviolet or gamma radiation [8]. The properties of NR and its products can be enhanced by the addition of different types of antioxidants, such as benzophenone, benzotriazole, and amines [8,9]. The organic antioxidants are unstable and toxic while inorganic ones are generally nontoxic and chemically stable under high temperature and UV irradiation $[8,10]$. 
Fillers are incorporated into rubber compounds to improve processability, cost reduction, and physical properties modifying the composites [11, 12]. One of the most important reasons for filler addition is related to make the production of the final product more economical [11].

In recent years, several inorganic and organic fillers were proposed, i.e., silanes [7, 13], unmodified and modified silica [14, 15], carbon nanotubes [2], carbon black [3, 13], starch, cellulose [16], titanium dioxide, zinc oxide [17, 18], magnesium hydroxide [19], silver nanoparticles [20], wood flour and other lignocellulosic fibers [21].

It is well known that the filler dispersion and filler-rubber interaction are two critical factors, which determine the performance of the composites [1, 22]. Other factors are structure, size, shape, surface area and surface reactivity of the filler particles [22-24].

Titanium dioxide is widely used as filler in polymer matrix composites. It is resulted from its useful properties, e.g., low-cost and high-effective pigment, high surface area per particle size connected with good effectiveness in UV protection $[8,25]$. Titanium dioxide is also a safe material for human and animals and possesses photocatalytic and bactericidal effects [25, 26]. Moreover, it was found that $\mathrm{TiO}_{2}$ particles can improve physical and mechanical properties of the polymeric materials [11]. Literature review is also shown that $\mathrm{TiO}_{2}$ particles have free surface hydroxyl groups, and this fact caused a small tendency for aggregation but good dispersion of the $\mathrm{TiO}_{2}$ in the polymer composites [11, 27]. Hayeemasae et al. [11] reported that the tensile strength of nano-sized $\mathrm{TiO}_{2}$ filled natural rubberbased composites is higher than that of the micro-sized $\mathrm{TiO}_{2}$ filled NR composites. The highest tensile strength was found at $6 \mathrm{phr}$ of nano and micro-sized $\mathrm{TiO}_{2}$ particles. Furthermore, the authors have found that the tensile modulus of the nano-sized $\mathrm{TiO}_{2}$ filled NR composite is slightly higher than that of the micro-sized one. This effect is probably caused by the smaller size of the nano-sized $\mathrm{TiO}_{2}$ particles resulted in their higher contact surface area. From others works it is known that the modulus is also related to the hardness of the filler [28].

Seentrakoon et al. [8] described natural rubber composites modified by rutile- $\mathrm{TiO}_{2}$ nanoparticle [abbreviated as $\mathrm{n}-\mathrm{TiO}_{2}(\mathrm{R})$ ] and micro particles. The authors showed that addition of $5 \mathrm{phr} n-\mathrm{TiO}_{2}(\mathrm{R})$ caused improvement in mechanical properties. Higher addition of mentioned $n-\mathrm{TiO}_{2}(\mathrm{R})$ particles resulted in decreasing of the properties. It was also presented that mechanical properties of the composites with 5 phr of micro- $\mathrm{TiO}_{2}(\mathrm{R})$ were lower than that of the composites with nano- $\mathrm{TiO}_{2}(\mathrm{R})$. It was also found that addition of $\mathrm{n}-\mathrm{TiO}_{2}$ improved the mechanical properties of the NR composites after UV irradiation. Seentrakoon et al. [8, 25] concluded that it is resulted from interfacial interaction between applied fillers and rubber matrix. The same facts about $\mathrm{TiO}_{2}$ effectiveness in protecting UV was showed by other authors. A lot of investigations confirm that $\mathrm{TiO}_{2}$ particles can be used as the anti-aging agent for synthetic and NR-bases materials [18, 25].

Another filler that is frequently used is silica, an excellent nonblack reinforcing filler [13]. But unfortunately it has lower compatibility with non-polar natural rubber due to its polar surface resulted from the presence of silanol groups. Some of the silica surface modification methods for improving the dispersion of silica in the rubber matrix are described in the literature [1, 13]. One of method was proposed by Zhong et al. [1] which explored the effect of silane modified silica (m-silica) on the performance of SBR-based composites. In the first step, they obtained ethylene thiourea-modified silica (silisa-s-ETU) by the surface modification of silica using vulcanization accelerator, i.e., ethylene thiourea. The results showed that silica-s-ETU/SBR composites are characterized by filler dispersion and higher mechanical properties than m-silica/SBR composites. Ahmed et al. [22] investigated the natural rubber composites filled with marble sludge (MS) and silica and reported that the addition of silica has more positive effect on the mechanical properties (e.g., tensile strength, modulus, tear strength and hardness) than marble sludge.

In the most cases, the fillers are used to reinforce rubber materials. However, rubber usually works in the dynamic conditions, but the rubber products possess a low-thermal conductivity which causes local generation and accumulation of heat. This problem can be also solved by adding fillers, such as stainless steel fiber, nano-zinc oxide [29], and carbon nanotubes [30] that enhance the thermal conductivity of the final materials.

In the presented work, natural rubber composites were prepared using titanium dioxide as filler. The main purpose of this work was to determine the effect of high filler content on the morphology and selected properties of the obtained natural rubber composites. Additionally, we have examined the effect of vulcanization time (10-25 $\mathrm{min}$ ) on the properties of the obtained natural rubber-based composites. It is well known that titanium dioxide is cheap inorganic filler which can be applied as a reinforcing agent and cost-reductive additive. The mechanical properties were analyzed in the context of tensile properties, hardness, abrasion resistance, tear strength, cyclic compression behavior and rebound resilience. The dynamic mechanical properties (i.e., storage and loss modulus and damping factor vs. temperature) and thermal stability were also determined and analyzed. 
Table 1 Formulations data of the prepared composites

\begin{tabular}{|c|c|c|c|c|c|}
\hline \multirow[t]{2}{*}{ Ingredients } & \multicolumn{5}{|c|}{ Quantities (parts per hundred parts of natural rubber) } \\
\hline & VNR & VNR15 & VNR25 & VNR45 & VNR85 \\
\hline Natural rubber & 100 & 100 & 100 & 100 & 100 \\
\hline Stearic acid & 3 & 3 & 3 & 3 & 3 \\
\hline Zinc oxide & 5 & 5 & 5 & 5 & 5 \\
\hline Stabilizer AR ${ }^{\mathrm{a}}$ & 1,5 & 1,5 & 1,5 & 1,5 & 1,5 \\
\hline Accelerator $\mathrm{T}^{\mathrm{b}}$ & 0,5 & 0,5 & 0,5 & 0,5 & 0,5 \\
\hline Machine oil & 2,5 & 2,5 & 2,5 & 2,5 & 2,5 \\
\hline $\mathrm{TiO}_{2}$ & - & $15(11.5 \mathrm{wt} \%)^{\mathrm{c}}$ & $25(17.8 \mathrm{wt} \%)^{\mathrm{c}}$ & $45(28.0 \mathrm{wt} \%)^{\mathrm{c}}$ & $85(42.4 \mathrm{wt} \%)^{\mathrm{c}}$ \\
\hline Sulfur & 3 & 3 & 3 & 3 & 3 \\
\hline
\end{tabular}

\section{Experimental}

\section{Materials}

The natural rubber used for preparing composites was supplied by TORIMEX (Poland). Stearic acid, sulfur powder and zinc oxide (POCh AVANTOR, Poland), stabilizer AR (CHMES, Poland), accelerator T (STANDARD, Poland), and oil machine (Nytex 810, Nynas, Poland) were other ingredients used during preparation of the rubber mixture. Titanium dioxide particles (Easy Chem, Poland) was used at the loading of $15,25,45,85$ parts by weight per hundred parts of natural rubber. The rubber mixture formulations are shown in Table 1. Titanium dioxide particles have approximate length of $5.86 \pm 1.25 \mu \mathrm{m}$ and width $0.98 \pm 0.21 \mu \mathrm{m}$.

\section{Preparation of rubber composites}

The mixtures of natural rubber, ingredients, and titanium dioxide particles were prepared on the laboratory tworoll mill during $15 \mathrm{~min}$. The ingredients were added in sequence presented in Table 1. The addition of each subsequent component follows good distribution of the earlier component. The rubber compounds were vulcanized by compression molding using a hydraulic press at $145^{\circ} \mathrm{C}$ with a pressure of 4-4.5 $\mathrm{MPa}$ at four various times of 10 , 15,20 and $25 \mathrm{~min}$.

\section{Testing methods}

\section{FTIR}

The chemical structures of the obtained natural rubber composites with titanium dioxide and natural rubber without $\mathrm{TiO}_{2}$ (reference sample) were investigated by means of Fourier transform infrared spectroscopy (FTIR) using a
Nicolet FTIR 8700 spectrophotometer (Thermo Electron Co., USA). The spectra were registered at room temperature for wavenumbers between 500 and $4500 \mathrm{~cm}^{-1}$ at nominal resolution $4 \mathrm{~cm}^{-1}$. Each spectrum was acquired with 64 scans.

\section{SEM}

The morphology of the cross-sections of prepared materials was determined using a Phenom G2 PRO scanning electron microscope (SEM, Phenom World, The Netherlands). The micrographs were prepared using desktop scanning electron microscope with accelerating voltage of $5 \mathrm{kV}$. Morphologies were obtained with several magnifications to observe dispersion of filler and its interaction with the natural rubber matrix.

\section{Swelling parameters}

The determination of all presented swelling parameters is described in the literature in the case of natural rubber composites filled with particulate and fibrous fillers [31-33]. The samples for test were cut from the compression molded sheets (obtained during the vulcanization process of the prepared natural rubber mixtures) and three samples (with the average mass equal ca. $1 \mathrm{~g}$ ) from each composite type were tested. The prepared composites samples were immersed in toluene at room temperature for $120 \mathrm{~h}$ to reach diffusion equilibrium (to obtain constant mass of immersed samples). Then samples were taken out from the solvent and adhered solvent was carefully removed using blotting paper, and mass of each sample was measured. After that the samples were dried in air for six days and in a laboratory oven at $80{ }^{\circ} \mathrm{C}$ to the moment when the constant weight was obtained. This procedure was the same as the one we used in the case of natural rubber composites filled with short jute fibers [32]. 
The swelling ratio (SR) is a mass of a solvent $\left(m_{\mathrm{as}}\right)$, i.e., toluene which was absorbed by the sample divided by the initial mass of the sample $\left(m_{\text {is }}\right)$. The mass of absorbed toluene was determined as difference between the mass of sample after $\left(m_{\mathrm{ss}}\right)$ and before swelling test $\left(m_{\mathrm{is}}\right)$. The swelling ratio was determined using Eq. (1) as follows:

$\mathrm{SR}=\frac{m_{\mathrm{ss}}-m_{\mathrm{is}}}{m_{\mathrm{is}}}=\frac{m_{\mathrm{as}}}{m_{\mathrm{is}}}$

The equilibrium swelling method (using the Flory-Rehner relationship, Eq. (2)) was used to determine the crosslink densities $(v)$ of the prepared natural rubber composites. Other swelling parameters, i.e., volume fraction of the rubber network in the swollen phase $\left(V_{\mathrm{r}}\right)$ and average molecular weight of the polymer between cross-links $\left(M_{\mathrm{c}}\right)$ were also determined as follows.

$v=\frac{-\ln \left(1-V_{\mathrm{r}}\right)-V_{\mathrm{r}}-\chi \cdot V_{\mathrm{r}}^{2}}{V_{\mathrm{s}} \cdot\left(V_{\mathrm{r}}^{\frac{1}{3}}-\frac{1}{2} \cdot V_{\mathrm{r}}\right)}=\frac{1}{M_{\mathrm{C}}}$

where, $V_{\mathrm{s}}$ is the molar volume of toluene $\left(V_{\mathrm{s}}=106.52 \mathrm{~cm}^{3} /\right.$ $\mathrm{mol}), \chi$ is the Flory-Huggins natural rubber-toluene interaction constant $(\chi=0.38)$.

\section{Static tensile test}

Tensile properties, including tensile strength, elongationat-break, and modulus at 100\% and 300\% elongation were measured using a universal testing machine Zwick/ Roell Z020 (Zwick, Germany) with cross-head speed $200 \mathrm{~mm} \mathrm{~min}^{-1}$, at the temperature $21^{\circ} \mathrm{C}$ according to ISO 37. The test samples were prepared in a standard dumbbell shape. The recorded results are averages of five independent measurements.

\section{Tear strength}

Tear strength was investigated with using a universal testing machine Zwick/Roell Z020 (Zwick, Germany), with cross-head speed $100 \mathrm{~mm} \mathrm{~min}^{-1}$ according to ISO 34-1. The test samples were prepared in a crescent shape with nick depth of $1 \mathrm{~mm}$, and all measurements were repeated five times.

\section{Cyclic compression and hysteresis}

The cyclic compression tests were carried out using a universal testing machine Zwick/Roell Z020 (Zwick, Germany). The cylindrical specimens (diameter $=7 \mathrm{~mm}$ and length $=24 \mathrm{~mm}$ ) were submitted to five compressiondecompression cycles at $50 \%$ of their original height and velocity of $0.7 \mathrm{~mm} \mathrm{~min}^{-1}$.

\section{Abrasion resistance}

The abrasion resistance of the obtained natural rubber composites was determined using a Schopper-Schlobach apparatus (Germany).The recorded results are presented as volume loss of the sample, in accordance with ISO 4649. For each prepared materials three independent tests were taken.

\section{Density}

Density was measured using an analytical balance RADWAG (Poland) by hydrostatic method with using methanol as an immersion medium, in accordance with ISO 2781, at room temperature and measurement was repeated five times for each prepared material.

\section{Hardness}

Hardness was determined according to ISO 868 standard using an electronic Shore type A (Zwick, Germany) and presented results are average from random ten points in one specimen.

\section{Rebound resilience}

Rebound resilience (elasticity) was investigated according to ISO 4662 standard. The measurements were carried out using a Schob type rebound tester, and the results are averages of ten independent tests.

\section{Dynamic mechanical thermal analysis}

Dynamic mechanical analysis (DMA) was carried out using a DMA Q800 analyzer (TA Instruments, USA) according to ASTM D6045, in a temperature range from -100 to $+150{ }^{\circ} \mathrm{C}$ at an operating frequency of $1 \mathrm{~Hz}$ and heating rate of $4{ }^{\circ} \mathrm{C} \mathrm{min}{ }^{-1}$ under air atmosphere. The samples dimensions were $2 \mathrm{~mm}$ thick, $10 \mathrm{~mm}$ wide and $40 \mathrm{~mm}$ long. The variation of storage modulus, loss modulus and tangent delta vs. temperature was determined.

\section{TGA}

Thermogravimetric analysis (TGA) was carried using a NETZSCH analyzer (TG 209F3, Netzsch, Germany). The samples were heated from 25 to $600{ }^{\circ} \mathrm{C}$ at a rate of $20{ }^{\circ} \mathrm{C} \mathrm{min}^{-1}$ under nitrogen atmosphere. 


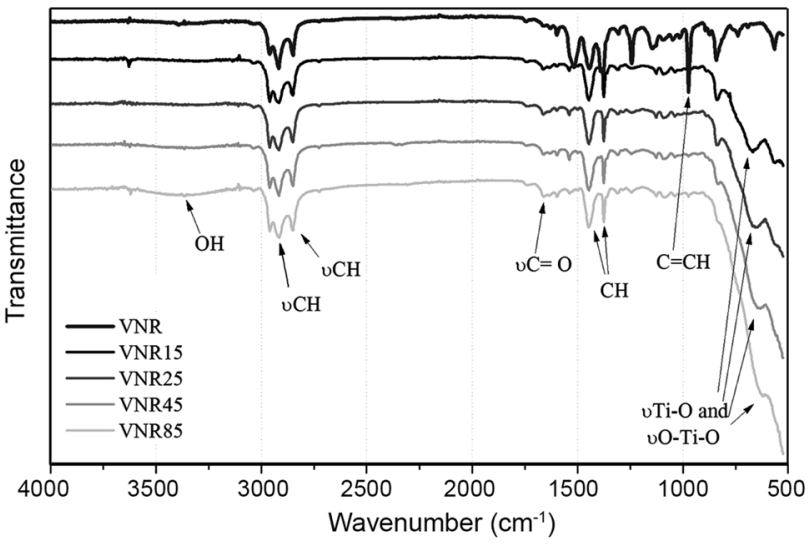

Fig. 1 FTIR spectra of the obtained natural rubber-based composites

\section{Results and discussion}

\section{FTIR analysis}

Chemical structure of the prepared natural rubber composites were confirmed by FTIR method and shown in Fig. 1. The analysis was performed for all materials. In all types of composites, samples with quite similar spectra were recorded which contain the bands assigned to $\mathrm{CH}_{2}$ symmetric and asymmetric stretching vibrations (2849$2916 \mathrm{~cm}^{-1}$ ) which were presented as a double peak, also is visible peak connected with $\mathrm{CH}_{3}$ asymmetric stretching vibration $\left(2958 \mathrm{~cm}^{-1}\right)$. The similar results were presented by Seentrakoon et al. [8].

The band at around $1660 \mathrm{~cm}^{-1}$ indicate the vibration of a hydrogen-bonded $\mathrm{C}=\mathrm{O}$ group, which is seen only for the filled rubber composites. Probably, the peak is related to the oxidation phenomena that occurred in the rubber matrix after the addition of $\mathrm{TiO}_{2}$, which is known as an oxidative agent $[8,34]$. It was observed the additional peak at $3370 \mathrm{~cm}^{-1}$ with increasing of $\mathrm{TiO}_{2}$ in the composite, which is assigned to the hydroxyl groups on the $\mathrm{TiO}_{2}$ particles surface. This peak can be observed for VNR45 and VNR85, but in the case of lower loadings of $\mathrm{TiO}_{2}$, it is not significant and for natural rubber vulcanizates, it is completely invisible. According to the literature, the peak of the hydroxyl groups on the $\mathrm{TiO}_{2}$ particles is emerged in the range of $3200-3600 \mathrm{~cm}^{-1}$ [35].

The unfilled composites exhibit the band at $970 \mathrm{~cm}^{-1}$, assigned to $\mathrm{C}=\mathrm{CH}$ deformation vibration [8] which disappeared after $\mathrm{TiO}_{2}$ addition into the rubber matrix. Also, this peak was appeared at the same time when the new band appeared at around $1400 \mathrm{~cm}^{-1}$ which is associated with the bending vibration of $\mathrm{CH}$ group. Additionally, we can see the broad and strong peak at approximately $600 \mathrm{~cm}^{-1}$, ascribed the absorption band of Ti-O and O-Ti-O flexural vibrations $[35,36]$. The VNR sample also exhibited the
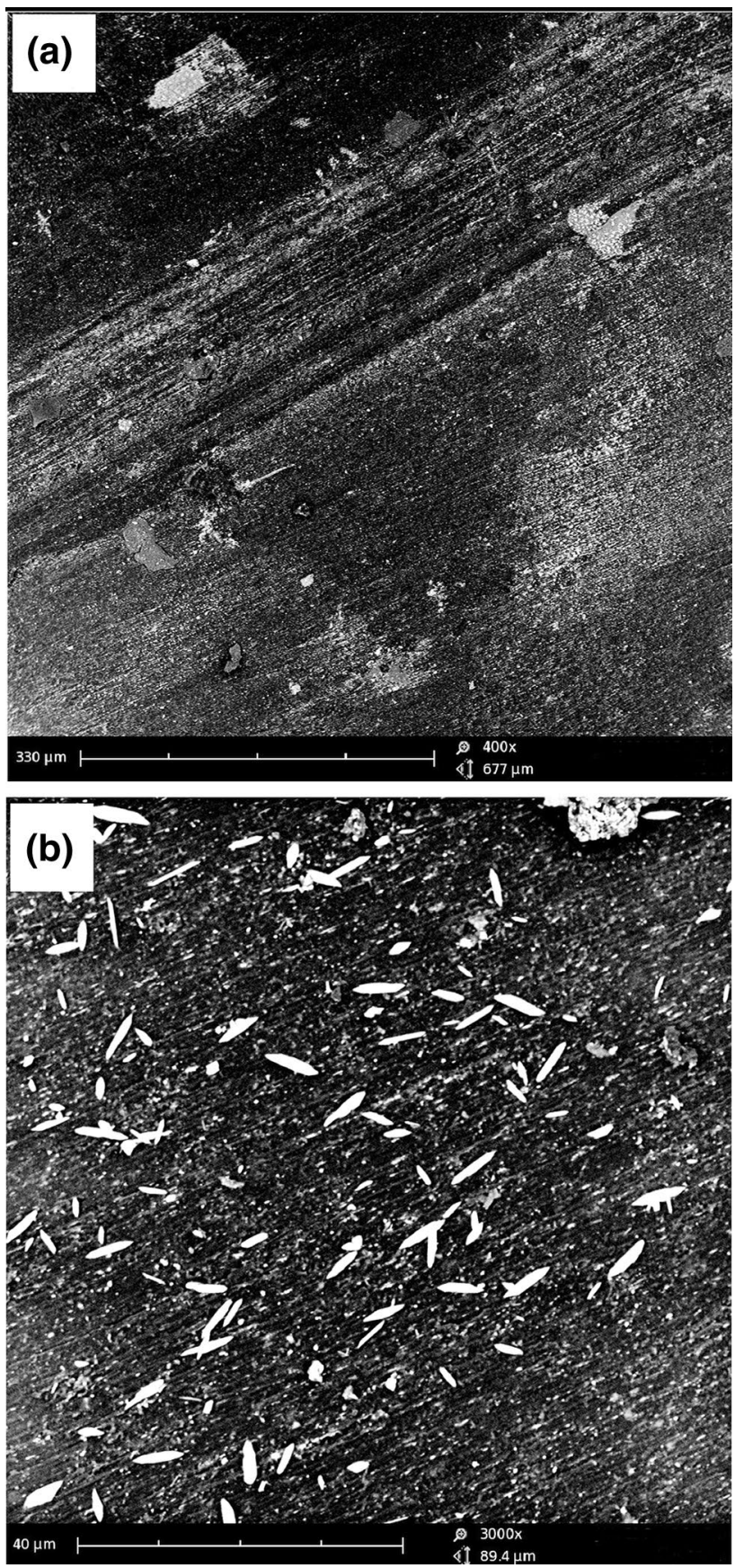

Fig. 2 SEM micrographs of VNR15

band at $970 \mathrm{~cm}^{-1}$, assigned to $\mathrm{C}=\mathrm{CH}$ deformation vibration [8].

Moreover, with increase in $\mathrm{TiO}_{2}$ loading in the prepared composites the mentioned peaks became wider and stronger as can be seen for VNR15-VNR85 samples. The results of FTIR analysis confirmed the presence of hydroxyl groups on the surface of the composites materials, therefore in accordance with the current state of knowledge, higher amount of hydroxyl groups on the surface 
may result in the improvement of hydrophilic nature of the composites surface [35].

\section{Morphology study}

The obtained SEM micrographs are shown in Figs. 2, 3, 4, 5. Generally, uniform dispersion of $\mathrm{TiO}_{2}$ in the natural rubber matrix is observed. However, the fillers tend to form agglomerates at higher loading. It is well known that good dispersion of the filler in the matrix is considered as a main factor to achieve good mechanical properties. The use of higher magnification allows observing the single $\mathrm{TiO}_{2}$ particle characterized by the longitudinal shapes. In Figs. 4 and $5, \mathrm{TiO}_{2}$ particles agglomeration can be seen, which the largest ones were observed for the VNR85 sample. It is known that the ability to agglomerate is heightening with increasing the loading of fillers.

\section{Swelling parameters study}

Swelling ratio (SR) decreasing with increasing content of titanium dioxide particles (as seen in Table 2), and this is resulted from the restricted possibility of toluene penetration in natural rubber composites. The restriction of swelling is connected with the presence of particulate filler (titanium dioxide absorb a much less amount of toluene than cross-linked natural rubber) and its interaction with natural rubber. Similar trend was observed by Ahmed et al. [31] in the marble sludge/natural rubber composites. Also, in the case of bio-based fibers similar behavior was observed, for example, in the natural rubber composites filled with short jute [32] and hemp [33] fibers.

The equilibrium swelling measurements permit to determine the cross-link densities of the prepared composites. The cross-link densities of the samples were determined using the Flory-Rehner relationship (measurements were performed in toluene) and this parameter is inversely proportional to the average molecular weight between the cross-links in the composite materials. Results from equilibrium swelling measurements are presented in Table 2. The increase in the amount of $\mathrm{TiO}_{2}$ particles in the NR matrix results in the increasing of the cross-link density and decreasing of the average molecular weight between crosslinks. This behavior is straightly related to the good interaction between surface of applied particulate filler and natural rubber matrix. The interaction between $\mathrm{TiO}_{2}$ particles and polymer chains causes restriction of natural rubber chains mobility, and the penetration of toluene through the NR matrix is hindered.

The increasing of cross-link density influences on the mechanical and thermal properties of the prepared materials, and it will be discussed in detail in the further parts of this work. The increasing of cross-link density with
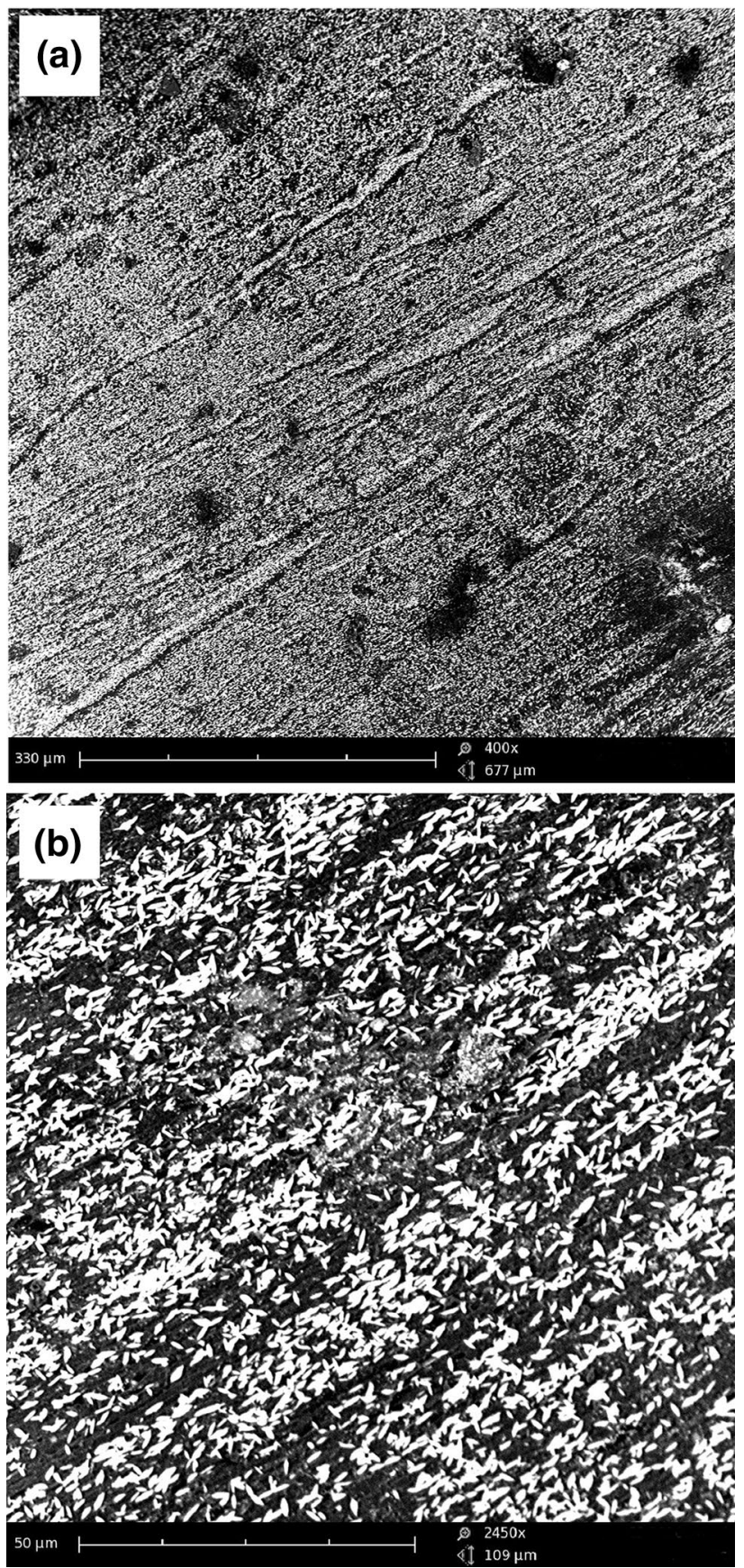

Fig. 3 SEM micrographs of VNR25

increasing content of the particulate or fibrous filler was observed by other authors, with marble sludge [31], short jute fibers [32] and hemp fibers [33] in the natural rubber composites.

\section{Static tensile test}

The results from static tensile test are shown in Table 3 . The natural rubber vulcanizates possess the highest 

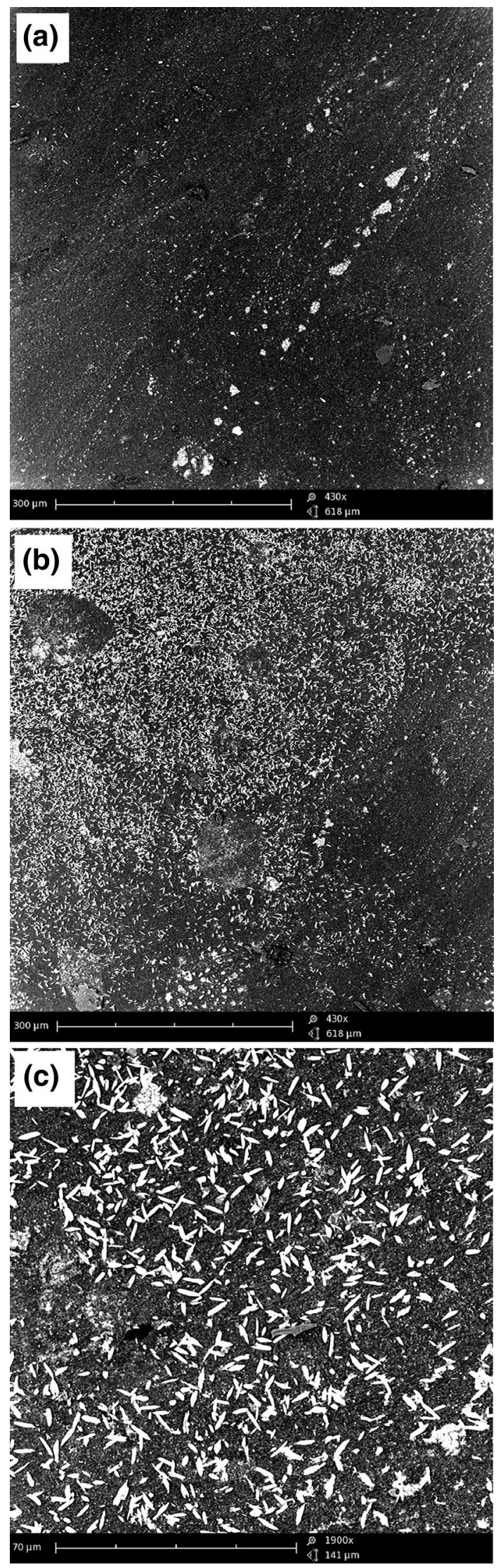

Fig. 4 SEM micrographs of VNR45
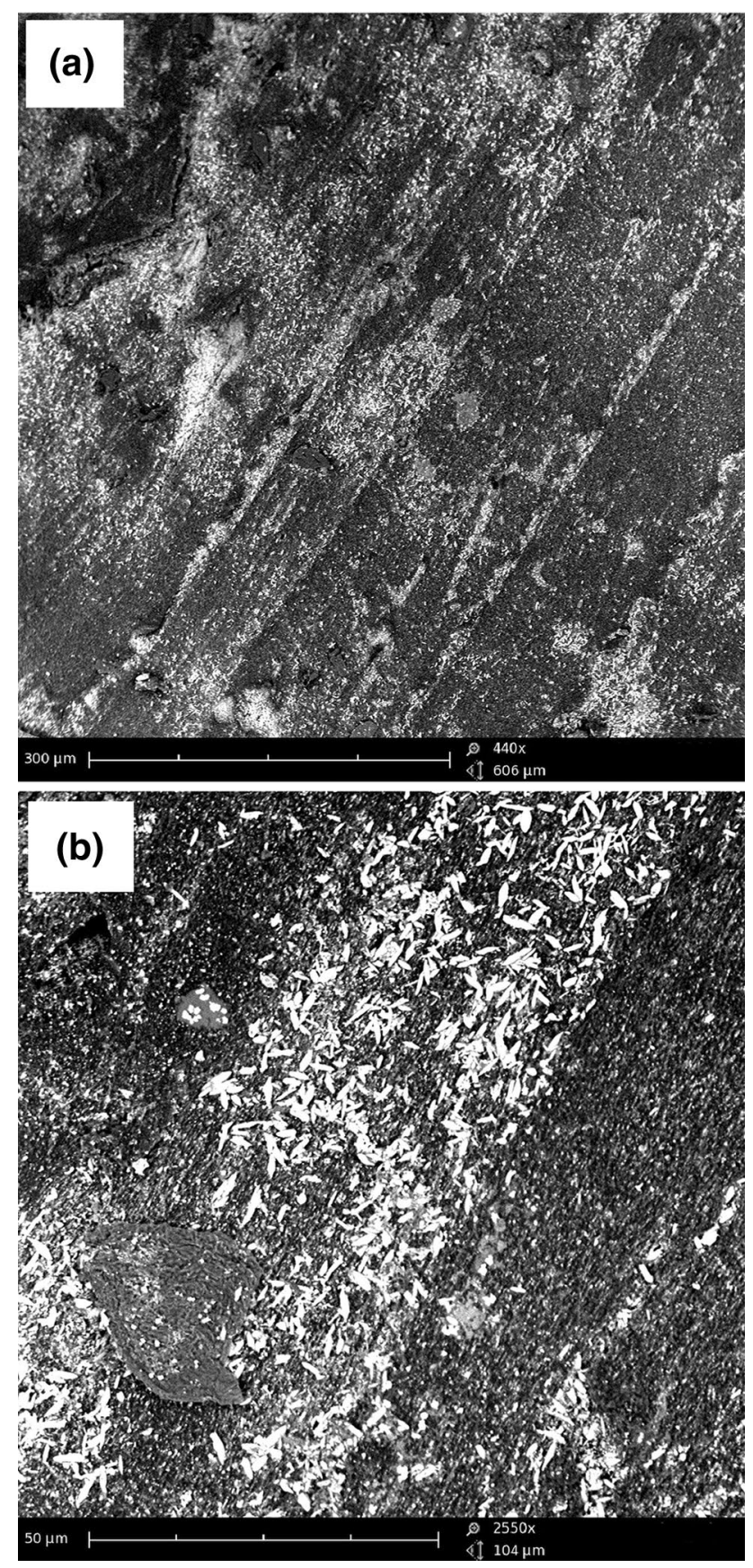

Fig. 5 SEM micrographs of VNR85

elongation-at-break (984\%) than natural rubber composites and the smallest tensile strength (in the case of compounds vulcanized in $10 \mathrm{~min}$ ) in comparison with the prepared composites. The highest tensile strength value (21.2 MPa) was observed for the sample prepared using 15 parts of titanium dioxide per hundred parts of the natural rubber for the vulcanization time $10 \mathrm{~min}$. The use of higher amounts of filler resulted in lowering of the tensile strength from 21.2 to $19.8 \mathrm{MPa}$ for the vulcanization time of $10 \mathrm{~min}$. 
Table 2 Effect of $\mathrm{TiO}_{2}$ particles on swelling properties of the prepared composites

\begin{tabular}{lllll}
\hline $\begin{array}{l}\text { Sample } \\
\text { code }\end{array}$ & $\begin{array}{l}\text { Swelling } \\
\text { ratio }(\mathrm{SR})(\%)\end{array}$ & $\begin{array}{l}\text { Volume fraction of a rubber } \\
\text { network in the swollen phase }\left(V_{\mathrm{r}}\right)\end{array}$ & $\begin{array}{l}\text { Cross-link density }(\nu) \\
10^{-4}\left(\mathrm{~mol} / \mathrm{cm}^{3}\right)\end{array}$ & $\begin{array}{l}\text { Molecular weight of the polymer } \\
\text { between cross-links }\left(\mathrm{M}_{\mathrm{c}}\right)\left(\mathrm{g} / \mathrm{mol}^{2}\right)\end{array}$ \\
\hline VNR & $319.1 \pm 1.7$ & $0.2026 \pm 0.0006$ & $1.5847 \pm 0.0114$ & $6310 \pm 45$ \\
VNR15 & $265.1 \pm 5.5$ & $0.2106 \pm 0.0009$ & $1.7312 \pm 0.0170$ & $5777 \pm 56$ \\
VNR25 & $251.1 \pm 0.7$ & $0.2126 \pm 0.0011$ & $1.7481 \pm 0.0217$ & $5652 \pm 69$ \\
VNR45 & $214.2 \pm 0.5$ & $0.2140 \pm 0.0003$ & $1.7967 \pm 0.0066$ & $5566 \pm 20$ \\
VNR85 & $160.5 \pm 1.1$ & $0.2247 \pm 0.0013$ & $2.0114 \pm 0.0270$ & $4972 \pm 66$ \\
\hline
\end{tabular}

Table 3 Tensile strength and elongation-at-break of different composites samples vulcanized at $10 \mathrm{~min}$

\begin{tabular}{|c|c|c|c|c|c|c|c|c|}
\hline \multirow{2}{*}{$\begin{array}{l}\text { Time } \\
\text { Sample code } \\
(-)\end{array}$} & \multicolumn{2}{|l|}{$10(\min )$} & \multicolumn{2}{|l|}{$15(\min )$} & \multicolumn{2}{|l|}{$20(\min )$} & \multicolumn{2}{|l|}{$25(\min )$} \\
\hline & $\begin{array}{l}\text { Tensile } \\
\text { strength } \\
(\mathrm{MPa})\end{array}$ & $\begin{array}{l}\text { Elongation-at- } \\
\text { break }(\%)\end{array}$ & $\begin{array}{l}\text { Tensile } \\
\text { strength } \\
(\mathrm{MPa})\end{array}$ & $\begin{array}{l}\text { Elongation-at- } \\
\text { break }(\%)\end{array}$ & $\begin{array}{l}\text { Tensile } \\
\text { strength } \\
(\mathrm{MPa})\end{array}$ & $\begin{array}{l}\text { Elongation-at- } \\
\text { break }(\%)\end{array}$ & $\begin{array}{l}\text { Tensile } \\
\text { strength } \\
(\mathrm{MPa})\end{array}$ & $\begin{array}{l}\text { Elongation-at- } \\
\text { break }(\%)\end{array}$ \\
\hline VNR & $18.3 \pm 0.5$ & $984 \pm 3$ & $13.9 \pm 0.2$ & $932 \pm 9$ & $14.6 \pm 1.0$ & $973 \pm 10$ & $14.4 \pm 0.6$ & $981 \pm 12$ \\
\hline VNR15 & $21.2 \pm 0.5$ & $703 \pm 15$ & $18.5 \pm 1.8$ & $670 \pm 7$ & $16.8 \pm 0.6$ & $692 \pm 12$ & $14.1 \pm 4.3$ & $674 \pm 24$ \\
\hline VNR25 & $20.2 \pm 0.2$ & $691 \pm 1$ & $15.6 \pm 0.2$ & $676 \pm 2$ & $18.7 \pm 0.1$ & $734 \pm 14$ & $15.6 \pm 0.8$ & $778 \pm 23$ \\
\hline VNR45 & $20.1 \pm 0.2$ & $698 \pm 2$ & $17.1 \pm 0.5$ & $679 \pm 6$ & $12.2 \pm 1.7$ & $695 \pm 26$ & $14.4 \pm 1.6$ & $744 \pm 11$ \\
\hline VNR85 & $19.8 \pm 1.2$ & $681 \pm 10$ & $16.6 \pm 3.7$ & $652 \pm 35$ & $13.4 \pm 0.1$ & $663 \pm 23$ & $10.3 \pm 2.3$ & $634 \pm 32$ \\
\hline
\end{tabular}

It was also found that optimal vulcanization time is equal $10 \mathrm{~min}$, because higher vulcanization time resulted in decreasing of the tensile properties, e.g., in the case of VNR15 sample the tensile strength decreased from 21.2 $\mathrm{MPa}$ for $10 \mathrm{~min}$ to $14.1 \mathrm{MPa}$ for $25 \mathrm{~min}$ vulcanization time. By use of 85 parts $\mathrm{TiO}_{2}$, tensile strength decreased to $10.3 \mathrm{MPa}$ for samples vulcanized at $25 \mathrm{~min}$. The similar trend was observed for elongation-at-break values. The reduction of mechanical properties when the vulcanization time was beyond $10 \mathrm{~min}$, was connected with the reversion of the vulcanization process.

Similar results were obtained by Hayeemasae et al. [11] which prepared natural rubber composites at the loading of $0,2,4,6$, and 8 parts of $\mathrm{TiO}_{2}$ particles per hundred parts of NR. Tensile strength and elongation-at-break decreased when the $\mathrm{TiO}_{2}$ content was above six parts by weight per hundred parts of the rubber. They reported that using of nano-sized $\mathrm{TiO}_{2}$ as filler for natural rubber composites resulted in better properties, as tensile modulus and tensile strength were more than those in the case of micro-sized $\mathrm{TiO}_{2}$-filled natural rubber composites [11].

This is resulted from better interaction between the NR matrix and the filler due to higher contact surface area between inorganic filler and polymer matrix, when nanosized $\mathrm{TiO}_{2}$ is used. The contact area between the filler and polymer matrix is one the important factor related to the obtain materials with improved properties. Addition of higher amounts of $\mathrm{TiO}_{2}$ particles can causes agglomeration of filler due to filler-filler interactions. Furthermore, the changes of tensile strength and elongation-at-break are sprightly connected with the dilution effect, and this is confirmed by other research works $[11,37]$.

The moduli at 100 and $300 \%$ elongation of the obtained composites are presented in Table 4. By increasing in the loading of $\mathrm{TiO}_{2}$ in the obtained composites the moduli was increased. The natural rubber vulcanizates possess the smallest mentioned earlier moduli. The addition of $\mathrm{TiO}_{2}$ caused reduction of elasticity, due to high hardness of introduced filler which resulted in more difficult deformation of material. Hayeemasae et al. [11] obtained similar results.

It is also known that moduli at 100 and $300 \%$ elongation are affected by the hardness of the fillers [28]. Moreover, with the increasing of vulcanization time the values of the mentioned moduli decreased. This is connected with the reversion of the vulcanization process, which is followed by increasing of the vulcanizates elasticity, and this fact is confirmed by the results of hardness and rebound resilience testing.

Many mechanisms of $\mathrm{TiO}_{2}$ interactions in the natural rubber composites were described in detail by Hayeemasae et al. [11]. One of the main important factors is the possibility of aggregate formation. At the low content of $\mathrm{TiO}_{2}$, the good dispersion and lower amount of aggregates were achieved. The stress transfer rate is almost comparable with that in the case of unfilled rubber materials. A large amount of fillers caused the opposite behavior, and the stress transfer became ineffective due to the breakdown of the aggregates and the energy was absorbed by the rubber 
Table 4 Moduli at 100\% and 300\% of composites vulcanized at four different times

\begin{tabular}{|c|c|c|c|c|c|c|c|c|}
\hline \multirow{2}{*}{$\begin{array}{l}\text { Vulcanized time (min) } \\
\text { Sample code }\end{array}$} & \multicolumn{2}{|l|}{10} & \multicolumn{2}{|l|}{15} & \multicolumn{2}{|l|}{20} & \multicolumn{2}{|l|}{25} \\
\hline & M100 (MPa) & M300 (MPa) & M100 (MPa) & M300 (MPa) & M100 (MPa) & M300 (MPa) & M100 (MPa) & M300 (MPa) \\
\hline VNR & $0.88 \pm 0.01$ & $2.12 \pm 0.02$ & $0.75 \pm 0.01$ & $1.83 \pm 0.02$ & $0.72 \pm 0.03$ & $1.73 \pm 0.03$ & $0.71 \pm 0.04$ & $1.68 \pm 0.02$ \\
\hline VNR15 & $0.97 \pm 0.01$ & $2.39 \pm 0.02$ & $1.05 \pm 0.04$ & $2.69 \pm 0.03$ & $0.90 \pm 0.01$ & $2.17 \pm 0.04$ & $0.85 \pm 0.01$ & $2.04 \pm 0.03$ \\
\hline VNR25 & $1.07 \pm 0.02$ & $2.78 \pm 0.01$ & $0.99 \pm 0.02$ & $2.50 \pm 0.04$ & $0.98 \pm 0.03$ & $2.33 \pm 0.02$ & $0.78 \pm 0.02$ & $1.79 \pm 0.01$ \\
\hline VNR45 & $1.17 \pm 0.03$ & $3.16 \pm 0.03$ & $1.12 \pm 0.04$ & $2.97 \pm 0.01$ & $0.83 \pm 0.01$ & $2.11 \pm 0.03$ & $0.89 \pm 0.02$ & $2.21 \pm 0.04$ \\
\hline VNR85 & $1.49 \pm 0.04$ & $4.18 \pm 0.04$ & $1.49 \pm 0.06$ & $3.98 \pm 0.05$ & $1.17 \pm 0.05$ & $3.02 \pm 0.04$ & $1.05 \pm 0.03$ & $2.72 \pm 0.07$ \\
\hline
\end{tabular}

chains on the filler surface [11]. All mentioned phenomena affect the mechanical properties of the prepared NR-based composites.

Improvement of polymer matrix composite properties depends on several factors, such as local polymer-filler interactions, filler-filler interactions and the geometry, size, dispersion and concentration of filler [25] According to the literature, $\mathrm{TiO}_{2}$ particles have large surface and improve interfacial interactions between fillers and NR matrix. It makes $\mathrm{TiO}_{2}$ as reinforcing filler in the natural rubber composites [8, 11].

The mechanical properties of composites increase with the better dispersion of filler in the NR matrix. It should be pointed that by increase in the filler amount, the interactions between filler particles can be formed in addition to filler-polymer interactions. The titanium dioxide particles due to the presence of hydroxyl groups on their surfaces are hydrophilic. The presence of hydroxyl groups allow to form the hydrogen bonding between filler and NR which result in the formation of stronger interface. It contributes to an effective stress transfer and improving of the mechanical properties of $\mathrm{TiO}_{2} / \mathrm{NR}$. The stronger bonding improves the wetting and adhesion of the polymer to the filler, due to the large surface area of filler. Furthermore, the smaller particle size of the filler is connected with the formation of better interfacial interactions between the inorganic filler and the polymer matrix $[8,25]$.

The improvement of the mechanical properties in the case of the composites filled with titanium dioxide was observed by several research groups. Esthappan et al. [38] found that in the case of polypropylene-based composites enhancement of the tensile strength and tensile modulus can be resulted from the interface formation between filler and polymer matrix, which can effectively transfer stress. The special interest is connected with $\mathrm{TiO}_{2}$ nanoparticles which can improve the tensile and flexural properties, fracture toughness and impact energy, but the improvement of these properties depends strongly on the filler content in the composite [39].

Unfortunately, nanoparticles can form aggregates due to high interactions between particles (electrostatic Van der Waals forces) at high content of filler. Aggregates are defects in the structure of composite, which are responsible for decreasing of the mechanical properties due to decreasing of contact area between the nanoparticles and polymer matrix $[39,40]$. It is very important to obtain good dispersion of titanium dioxide particles in polymer matrix, because it results in a more uniform stress distribution in material and minimizes stress-concentration (like in the case of aggregates). Generally, the well dispersed filler results in the improvement of mechanical properties [39].

As was mentioned earlier the effectiveness of stress transfer between the natural rubber matrix and titanium dioxide particles is enhanced by the interaction of filler with polymer matrix. The relationship between the tensile strength of polymer composites and interfacial interactions was described by Pukanszky [41] and can be calculated using Eq. (3) as follows:

$\sigma_{\mathrm{c}}=\sigma_{\mathrm{m}} \cdot\left(\frac{1-V_{p}}{1+2.5 \cdot V_{p}}\right) \cdot e^{B \cdot V_{p}}$

where, $\sigma_{\mathrm{c}}$ is the tensile strength of the prepared composites (i.e., VNR15, VNR25, VNR45 or VNR85), $\sigma_{\mathrm{m}}$ is the tensile strength of the polymer matrix (i.e., natural rubber vulcanizate without filler coded as VNR), $V_{\mathrm{p}}$ is the filler volume fraction (determined using the method presented by Leong et al. [42]), and $B$ is the parameter related to the matrixfiller interactions.

The filler volume fractions and matrix-filler interaction parameters (calculated from Pukanszky relationship) for the prepared natural rubber composites filled with $\mathrm{TiO}_{2}$ particles are presented in Table 5. The calculations were performed only for composites obtained at optimal vulcanization time, i.e., $10 \mathrm{~min}$. The increase in the amount of $\mathrm{TiO}_{2}$ particles (increase in filler volume fraction) in the prepared composites result in decreasing of matrix-filler interaction parameter resulted from the more filler-filler interactions which occurs due to the presence of hydroxyl groups on the surface of $\mathrm{TiO}_{2}$ particles and formation of filler aggregates due to high interactions between the particles (as a result of electrostatic Van der Waals forces) at a high content of filler. Similar behavior was observed by Nath et al. [43] in the case of fly ash-isotactic polypropylene composites. 
Table $5 \mathrm{TiO}_{2}$ content effect in matrix-filler interaction parameter calculated from Pukanszky relationship

\begin{tabular}{lll}
\hline Sample code & $\begin{array}{l}\text { Volume fraction of } \\
\text { filler, } V_{\mathrm{p}}\end{array}$ & $\begin{array}{l}\text { Polymer matrix-filler } \\
\text { interaction parameter, } B\end{array}$ \\
\hline VNR15 & 0.028 & 8.53 \\
VNR25 & 0.047 & 5.48 \\
VNR45 & 0.082 & 4.46 \\
VNR85 & 0.144 & 3.76 \\
\hline
\end{tabular}

Table 6 Tear strength values of composites vulcanized at different times

\begin{tabular}{llrrr}
\hline $\begin{array}{l}\text { Vulcanized time } \\
\text { (min) }\end{array}$ & \multicolumn{1}{l}{10} & \multicolumn{1}{l}{20} & \multicolumn{1}{l}{25} \\
\hline Sample code & \multicolumn{4}{l}{ Tear Strength $(\mathrm{N} / \mathrm{mm})$} \\
VNR & $28.4 \pm 0.8$ & $20.7 \pm 5.2$ & $22.8 \pm 3.0$ & $23.6 \pm 4.8$ \\
VNR15 & $33.6 \pm 5.6$ & $12.4 \pm 3.7$ & $10.6 \pm 3.2$ & $10.7 \pm 3.5$ \\
VNR25 & $35.0 \pm 5.6$ & $8.4 \pm 0.2$ & $9.5 \pm 1.1$ & $11.6 \pm 3.0$ \\
VNR45 & $30.9 \pm 5.9$ & $21.2 \pm 6.7$ & $7.7 \pm 0.5$ & $8.1 \pm 0.6$ \\
VNR85 & $32.1 \pm 3.5$ & $25.5 \pm 3.5$ & $22.1 \pm 2.5$ & $21.4 \pm 3.6$ \\
\hline
\end{tabular}

\section{Tear strength}

Tear strength of the obtained rubber composites are presented in Table 6. The highest tear strength values were observed for the samples vulcanized at $10 \mathrm{~min}$, and this also suggest that it is proper vulcanization time. Tear strength of all samples was increased with increase in $\mathrm{TiO}_{2}$ loading up to $25 \mathrm{phr}$. The samples without filler exhibit the lowest tear strength values. This trend indicated a good interaction between filler surface with NR matrix, which resulted in cracks growth inhibition in the obtained rubber composites.

\section{Cyclic compression}

The cyclic compression stress-strain curves for all prepared composites are shown in Fig. 6. The loading, unloading, dissipated energy values in each cycle and the difference between energy dissipated in the first and fifth cycle are presented in Table 7 . The compression cycles were obtained until 50\% compression. During compressiondecompression (removing of loads) cycle, a certain amount of energy can be absorbed-released by the material. The use of higher amounts of filler caused increasing of energy dissipated from 0.075 to $0.181 \mathrm{~J}$ for the vulcanization time equal to $10 \mathrm{~min}$. The lowest value of loading and unloading energy was observed for neat natural rubber vulcanizates. The loss of energy during each cycle is connected with the

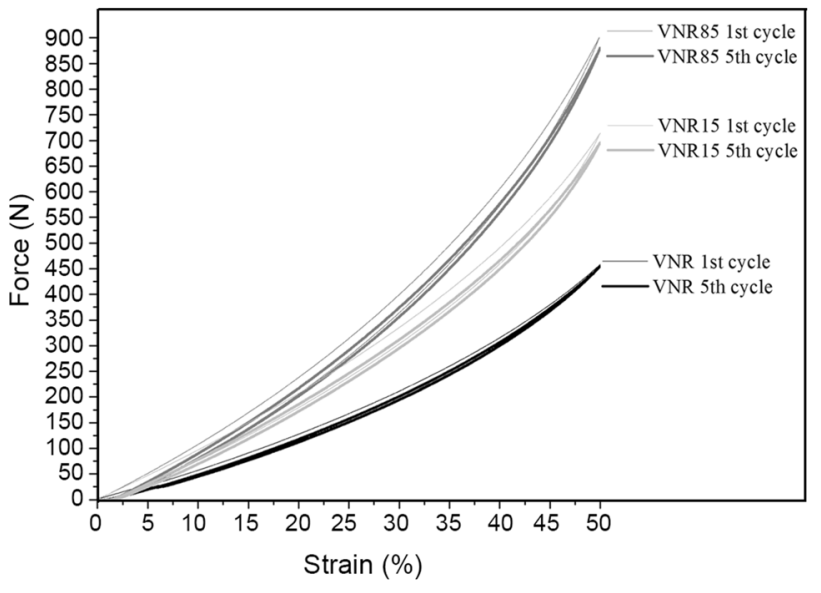

Fig. 6 First and fifth cycle compression stress-strain curves for VNR, VNR15, VNR85 at 10 min vulcanized time

deformation of the rubber matrix. It could be attributed to the interfacial interactions between $\mathrm{TiO}_{2}$ and NR chains. The occurring interactions between polymer matrix and filler increased the work required for the deformation of the composites, because the energy is dissipated on the titanium dioxide particles. The addition of $\mathrm{TiO}_{2}$ into soft matrix decreased the effectiveness of the stress transfer into rubber matrix and increased the work required to deform the composite. In all samples, permanent deformation at the end of their first cycle was observed, which indicated a change in the microstructure of the samples as a result of loading cycles and it mainly depended on the maximum strain level. This observation is also known from the literature [44].

\section{Abrasion resistance and density}

The abrasion resistance and density of $\mathrm{TiO}_{2} / \mathrm{NR}$ vulcanizates are shown in Tables 8 and 9. The addition of $\mathrm{TiO}_{2}$ to the rubber materials significantly improved the abrasion resistance. The lowest abrasion resistance was appeared in the natural rubber vulcanizates sample without $\mathrm{TiO}_{2}$. The values of the mentioned properties are strongly dependent on the amount of the used filler. The highest abrasion resistance for filled composites $\left(0.024 \mathrm{~cm}^{3}\right)$ was observed for sample VNR15 (vulcanization time of $10 \mathrm{~min}$ ). The increase in loading of filler in the final material resulted in the lowering of abrasion resistance, but even in the $\mathrm{TiO}_{2}$ content of $85 \mathrm{phr}$, the abrasion resistance was higher than that of the unfilled material. The increasing of the vulcanization time also resulted in decreasing of the abrasion resistance. The exceeding of the optimum vulcanization time is followed by regression of vulcanization process and thermal degradation of the obtained material, and consequently decreasing of the abrasion resistance. 
Table 7 Hysteresis characteristic of samples vulcanized for $10 \mathrm{~min}$

\begin{tabular}{|c|c|c|c|c|c|}
\hline Sample code & Cycle number & Loading energy $W_{\mathrm{c}}(\mathrm{J})$ & Unloading energy $W_{\mathrm{RC}}(\mathrm{J})$ & Dissipated energy $\Delta \mathrm{H}(\mathrm{J})$ & $\Delta \mathrm{H}_{1-5}(\mathrm{~J})$ \\
\hline \multirow[t]{5}{*}{ VNR } & 1 & 2.225 & 2.093 & 0.132 & \multirow[t]{5}{*}{0.075} \\
\hline & 2 & 2.151 & 2.079 & 0.072 & \\
\hline & 3 & 2.136 & 2.072 & 0.064 & \\
\hline & 4 & 2.129 & 2.067 & 0.061 & \\
\hline & 5 & 2.122 & 2.065 & 0.057 & \\
\hline \multirow[t]{5}{*}{ VNR15 } & 1 & 3.488 & 3.191 & 0.297 & \multirow[t]{5}{*}{0.151} \\
\hline & 2 & 3.324 & 3.150 & 0.174 & \\
\hline & 3 & 3.284 & 3.125 & 0.158 & \\
\hline & 4 & 3.259 & 3.108 & 0.151 & \\
\hline & 5 & 3.238 & 3.093 & 0.146 & \\
\hline \multirow[t]{5}{*}{ VNR85 } & 1 & 4.218 & 3.886 & 0.333 & \multirow[t]{5}{*}{0.181} \\
\hline & 2 & 4.053 & 3.865 & 0.188 & \\
\hline & 3 & 4.004 & 3.838 & 0.167 & \\
\hline & 4 & 3.972 & 3.815 & 0.157 & \\
\hline & 5 & 3.948 & 3.796 & 0.152 & \\
\hline
\end{tabular}

Table 8 Abrasion resistance of composites vulcanized at different times

\begin{tabular}{|c|c|c|c|c|}
\hline Vulcanized time (min) & 10 & 15 & 20 & 25 \\
\hline Sample code & \multicolumn{4}{|c|}{ Abrasion resistance $\left(\mathrm{cm}^{3}\right)$} \\
\hline VNR & $0.063 \pm 0.022$ & $0.125 \pm 0.043$ & $0.140 \pm 0.055$ & $0.186 \pm 0.035$ \\
\hline VNR15 & $0.024 \pm 0.004$ & $0.035 \pm 0.011$ & $0.037 \pm 0.003$ & $0.051 \pm 0.010$ \\
\hline VNR25 & $0.035 \pm 0.003$ & $0.035 \pm 0.001$ & $0.054 \pm 0.007$ & $0.054 \pm 0.005$ \\
\hline VNR45 & $0.037 \pm 0.002$ & $0.041 \pm 0.003$ & $0.059 \pm 0.003$ & $0.071 \pm 0.010$ \\
\hline VNR85 & $0.033 \pm 0.023$ & $0.053 \pm 0.001$ & $0.055 \pm 0.005$ & $0.071 \pm 0.004$ \\
\hline
\end{tabular}

Table 9 Density of composites vulcanized at different times

\begin{tabular}{llllr}
\hline Vulcanized time $(\mathrm{min})$ & \multicolumn{1}{l}{10} & \multicolumn{1}{l}{20} & \multicolumn{1}{l}{25} \\
\hline Sample code & Density $\left(\mathrm{g} \mathrm{cm}^{-3}\right)$ & & & \\
VNR & $0.9679 \pm 0.0001$ & $0.9677 \pm 0.0034$ & $0.9641 \pm 0.0035$ & $0.9665 \pm 0.007$ \\
VNR15 & $1.0678 \pm 0.0022$ & $1.0644 \pm 0.0006$ & $1.0654 \pm 0.0004$ & $1.0645 \pm 0.0004$ \\
VNR25 & $1.1182 \pm 0.0003$ & $1.1184 \pm 0.0003$ & $1.1184 \pm 0.008$ & $1.1177 \pm 0.0003$ \\
VNR45 & $1.2264 \pm 0.0003$ & $1.2276 \pm 0.0005$ & $1.2255 \pm 0.0001$ & $1.4163 \pm 0.0005$ \\
VNR85 & $1.4163 \pm 0.0005$ & $1.4161 \pm 0.0006$ & $1.4167 \pm 0.0004$ & $1.4168 \pm 0.0007$ \\
\hline
\end{tabular}

Density of the produced composites is in the range $1.0678-1.416 \mathrm{~g} \mathrm{~cm}^{-3}$ and density of the unfilled natural rubber vulcanizates is $0.9679 \mathrm{~g} \mathrm{~cm}^{-3}$. As is shown in Table 9, density values of the obtained composites were increased with the increase in the loading titanium dioxide resulted from higher density of $\mathrm{TiO}_{2}$ particles in comparison with the vulcanized natural rubber. The smallest density was observed for natural rubber with 15 parts per titanium dioxide per hundred parts of natural rubber. Generally, it was observed that the densities of materials are very similar and independent of the vulcanization time.

\section{Hardness and rebound resilience}

The hardness and rebound resilience of the obtained materials are presented in Table 10. The results were depended on the content of titanium dioxide and vulcanization time. Hardness of the samples was in the range of 46.4 $54.3^{\circ} \mathrm{ShA}$ for $10 \mathrm{~min}$ vulcanization time. It was also found that optimal vulcanization time was $10 \mathrm{~min}$, because higher vulcanization time resulted in decreasing of the hardness and rebound resilience. The natural rubber vulcanizates without filler possessed the smallest hardness and with 
Table 10 Hardness and rebound resilience of composites vulcanized at four different times

\begin{tabular}{|c|c|c|c|c|c|c|c|c|}
\hline \multirow{2}{*}{$\begin{array}{l}\text { Vulcanized } \\
\text { time (min) } \\
\text { Sample } \\
\text { code (-) }\end{array}$} & \multicolumn{2}{|l|}{10} & \multicolumn{2}{|l|}{15} & \multicolumn{2}{|l|}{20} & \multicolumn{2}{|l|}{25} \\
\hline & $\begin{array}{l}\text { Hardness } \\
\left({ }^{\circ} \mathrm{Sh} \mathrm{A}\right)\end{array}$ & $\begin{array}{l}\text { Rebound } \\
\text { resilience (\%) }\end{array}$ & $\begin{array}{l}\text { Hardness } \\
\left({ }^{\circ} \mathrm{Sh} \mathrm{A}\right)\end{array}$ & $\begin{array}{l}\text { Rebound } \\
\text { resilience (\%) }\end{array}$ & $\begin{array}{l}\text { Hardness } \\
\left({ }^{\circ} \mathrm{Sh} \mathrm{A}\right)\end{array}$ & $\begin{array}{l}\text { Rebound } \\
\text { resilience (\%) }\end{array}$ & $\begin{array}{l}\text { Hardness } \\
\left({ }^{\circ} \mathrm{Sh} \mathrm{A}\right)\end{array}$ & $\begin{array}{l}\text { Rebound } \\
\text { resilience (\%) }\end{array}$ \\
\hline VNR & $39.7 \pm 0.9$ & $43.8 \pm 2.1$ & $37.5 \pm 0.2$ & $41.2 \pm 1.6$ & $36.8 \pm 0.4$ & $40.2 \pm 1.9$ & $36.0 \pm 0.4$ & $39.4 \pm 2.0$ \\
\hline VNR15 & $46.4 \pm 0.6$ & $50.3 \pm 3.1$ & $45.6 \pm 0.3$ & $49.0 \pm 2.6$ & $44.9 \pm 0.8$ & $51.1 \pm 4.3$ & $43.1 \pm 0.8$ & $51.2 \pm 2.3$ \\
\hline VNR25 & $46.5 \pm 1.8$ & $52.1 \pm 2.4$ & $46.2 \pm 0.3$ & $52.0 \pm 2.7$ & $44.6 \pm 0.3$ & $48.0 \pm 2.8$ & $43.6 \pm 0.5$ & $47.8 \pm 2.7$ \\
\hline VNR45 & $50.2 \pm 0.3$ & $49.9 \pm 2.7$ & $46.8 \pm 1.0$ & $49.9 \pm 2.5$ & $44.9 \pm 1.0$ & $46.6 \pm 2.9$ & $44.4 \pm 0.6$ & $45.7 \pm 2.1$ \\
\hline VNR85 & $54.3 \pm 0.5$ & $50.5 \pm 2.0$ & $52.9 \pm 0.7$ & $47.4 \pm 2.1$ & $51.2 \pm 0.3$ & $45.7 \pm 2.5$ & $49.5 \pm 0.3$ & $43.5 \pm 2.1$ \\
\hline
\end{tabular}

increase in the loading of the filler, hardness was enhanced. Therefore, the highest hardness $\left(54.3^{\circ} \mathrm{ShA}\right)$ was observed for the sample with 85 parts per titanium dioxide hundred parts of natural rubber.

When the vulcanization time increased the cure time, hardness of the prepared rubber vulcanizates decreased. As stated above, the increasing of the vulcanization time resulted in thermal degradation of the composites and decreasing their hardness. The rebound resilience was in the range 43.5-52.9\% and vulcanization time-independent. It can be concluded that the rebound resilience was depended strongly on the filler distribution in the elastomeric matrix. It can be concluded that results were dependent on the places, where the pendulum fall on the sample. When the pendulum hit on the surface where the large agglomerates were present, filler received energy of impact and this resulted in the lower rebound resilience than when the pendulum hit on the elastomeric surface.

\section{Dynamic mechanical thermal analysis}

Results from dynamic mechanical thermal analysis (DMTA) of the prepared composites are shown in Figs. 7, 8, 9. In the temperature range from -100 to $0{ }^{\circ} \mathrm{C}$, the natural rubber composites have generally higher storage modulus $\left(E^{\prime}\right)$ in comparison with the neat natural rubber vulcanizates. As can be seen in Fig. 7 use of 85 parts $\mathrm{TiO}_{2}$ per hundred parts of natural rubber significantly increased the storage modulus in the glassy region, which is connected with the enhancement of composite stiffness due to the presence of the inorganic filler characterized by high hardness.

In the Fig. 8, loss modulus ( $\left.\mathrm{E}^{\prime \prime}\right)$ dependence on temperature for all prepared materials is presented. Loss modulus of composites is in the range of 846-1200 MPa. Generally, the maximum value of the loss modulus increased with increase in the amount of filler content, which is connected with higher loss energy. The glass transition temperature is determined as a temperature at which $\tan \delta$ reaches its maximum value. The tangent delta dependence on the

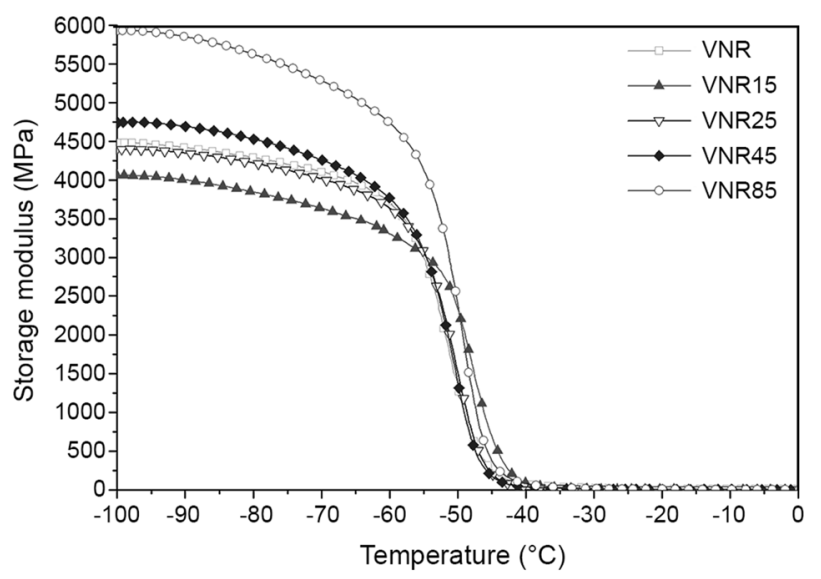

Fig. 7 Storage modulus changes vs. temperature of different composites samples vulcanized at $10 \mathrm{~min}$

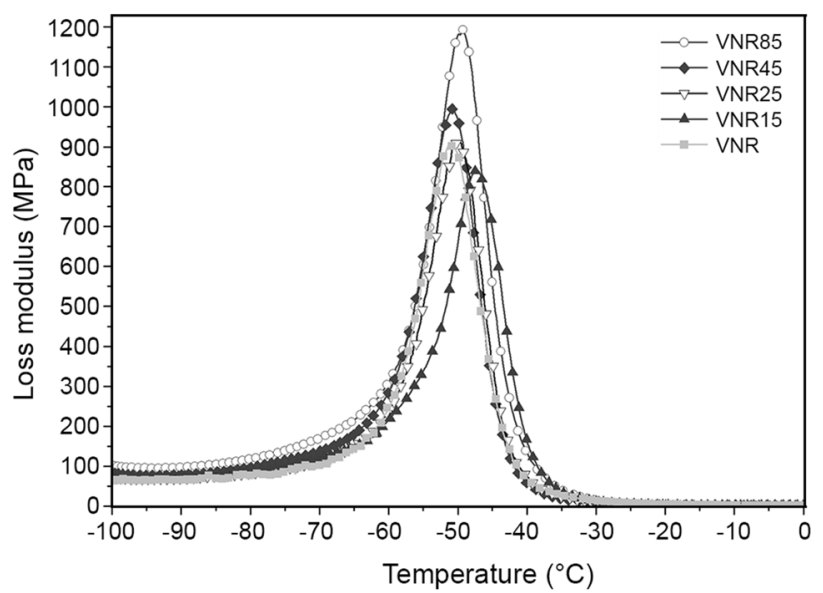

Fig. 8 Loss modulus changes vs. temperature of different composites samples vulcanized at $10 \mathrm{~min}$

temperature (Fig. 10; Table 11) for natural rubber composites showed that the height of $\tan \delta$ peak is affected by the amount of filler. 


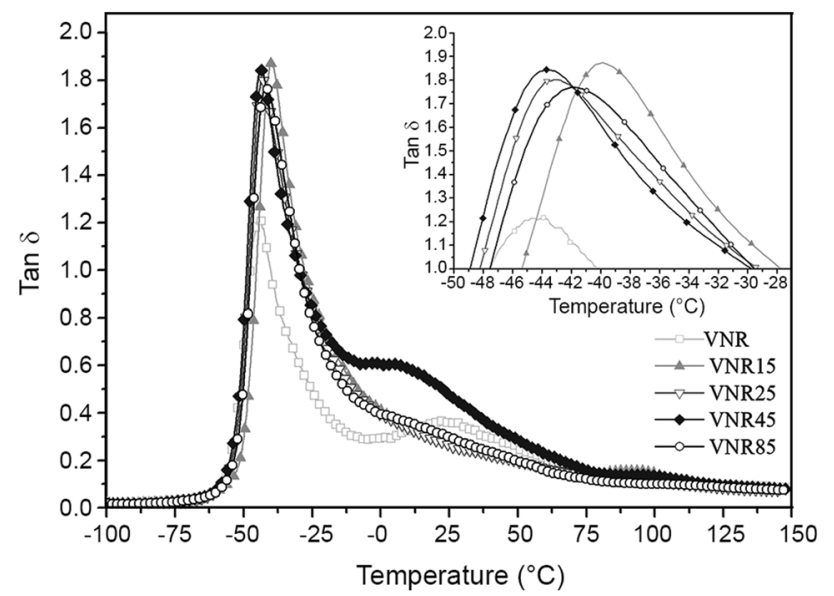

Fig. 9 Temperature dependence of $\tan \delta$ of different composites samples vulcanized at $10 \mathrm{~min}$

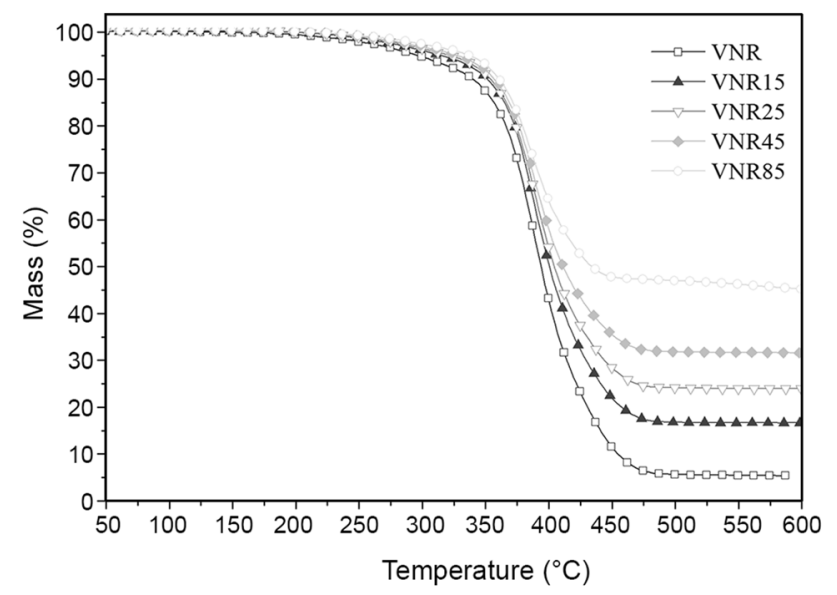

Fig. 10 TGA curves of different composite samples and reference sample

\section{Thermogravimetric analysis}

Thermal stability of the prepared natural rubber composites are shown in Figs. 10 and 11 (TGA and DTG curves). The characteristic temperatures of thermal decomposition are presented in Table 12. As can be seen thermal degradation of VNR begins at $200{ }^{\circ} \mathrm{C}$. All natural rubber composites showed a one stage thermal degradation. It is evident that the highest thermal stability is exhibited by VNR85. In Fig. 11, it is also discernible the existence of one stage thermal decomposition for all materials. The highest rate of thermal decomposition was observed at ca. $390{ }^{\circ} \mathrm{C}$ for all prepared materials. Addition of $\mathrm{TiO}_{2}$ particles to NR resulted in the increase of thermal stability, which was due to the high thermal stability of the applied inorganic
Table 11 Glass transition temperature of the obtained composites determined by DMA method

\begin{tabular}{lll}
\hline Sample code & $T_{\mathrm{g}}\left({ }^{\circ} \mathrm{C}\right)$ & $\tan \delta$ \\
\hline VNR & -44.5 & 1.21 \\
VNR15 & -40.0 & 1.87 \\
VNR25 & -43.0 & 1.81 \\
VNR45 & -43.6 & 1.84 \\
VNR85 & -42.0 & 1.77 \\
\hline
\end{tabular}

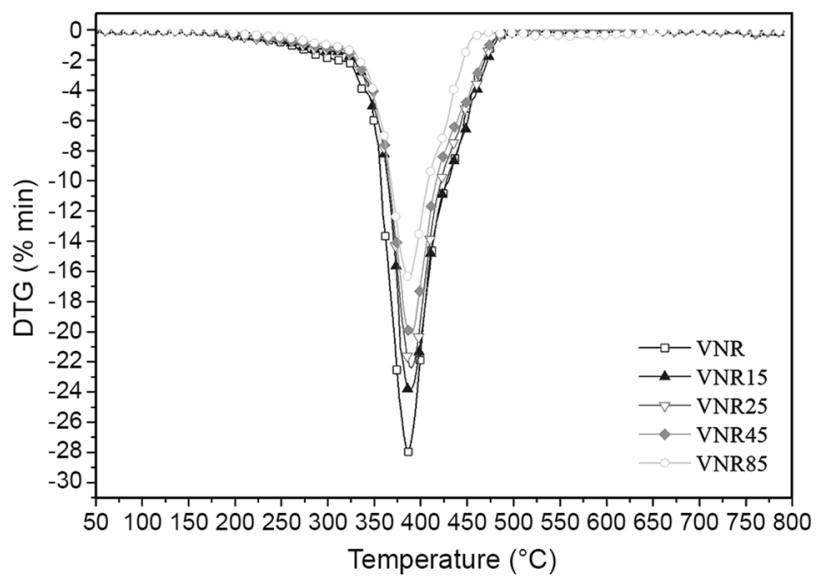

Fig. 11 DTG curves of different composite samples and reference sample

filler. The incorporation of titanium dioxide can improve the mechanical properties and thermal stability of the prepared composites. It is also observable that the maximum degradation temperature for the composites filled with 85 parts $\mathrm{TiO}_{2}$ by weight per hundred parts of rubber is slightly higher than the other samples. Natural rubber composites showed higher thermal stability than the neat natural rubber vulcanizates. The char yield at $600{ }^{\circ} \mathrm{C}$ is in the good correlation with the percentage weight content of titanium dioxide in the prepared composites (Tables 1,11).

The improvement of the thermal stability of the polymer matrix composites can be obtained by the presence of fillers (e.g., $\mathrm{TiO}_{2}$ particles) which can interact with the polymer matrix. The relatively strong interactions between the filler surfaces and polymer chains resulted in restriction of thermal movements (mobility) of polymer chains [38]. Esthappan et al. [45] suggested that in the case of polypropylene composites filled with $\mathrm{TiO}_{2}$ particles, the good interfacial interactions restricted the mobility of the polymer chains and made the scission of polymer harder, and due to this reasons the degradation temperature is shifted to the higher temperatures. 
Table 12 Thermal stability of the obtained composites

\begin{tabular}{lllllll}
\hline Sample code & $T_{5}\left({ }^{\circ} \mathrm{C}\right)$ & $T_{10}\left({ }^{\circ} \mathrm{C}\right)$ & $T_{30}\left({ }^{\circ} \mathrm{C}\right)$ & $T_{50}\left({ }^{\circ} \mathrm{C}\right)$ & $T_{\max }\left({ }^{\circ} \mathrm{C}\right)$ & Char yield at $600{ }^{\circ} \mathrm{C}(\%)$ \\
\hline VNR & 294.4 & 339.5 & 376.9 & 394.5 & 386.9 & 5.4 \\
VNR15 & 313.2 & 350.7 & 383.2 & 400.7 & 387.9 & 16.3 \\
VNR25 & 322.1 & 352.1 & 384.6 & 404.6 & 389.3 & 23.5 \\
VNR45 & 327.8 & 355.3 & 387.8 & 412.8 & 389.7 & 31.2 \\
VNR85 & 336.6 & 359.1 & 391.7 & 434.2 & 387.3 & 44.3 \\
\hline
\end{tabular}

\section{Conclusion}

The results showed that using titanium dioxide as filler allows obtaining materials with improved mechanical properties and thermal stability in comparison with the neat natural rubber vulcanizates. Prepared natural rubber composites exhibited higher tensile strength, hardness, moduli at 100 and $300 \%$ elongation, and abrasion resistance than the unfilled natural rubber vulcanizates. SEM analysis showed generally good dispersion of the filler in the elastomeric matrix. However, inorganic filler at higher loadings showed ability to form agglomerates, which are responsible for decrease of mechanical properties. It was generally observed that even with decline in mechanical properties by increase in $\mathrm{TiO}_{2}$ contents, the obtained values from mechanical tests were higher than those in the case of the unfilled natural rubber. Moreover, composites with $85 \mathrm{phr}$ of titanium dioxide have surprisingly good mechanical properties and thermal stability. Titanium dioxide as a filler has a very good potential for production new materials with better mechanical properties and thermal stability in comparison with the neat natural rubber vulcanizates. This kind of material is a good candidate for specific applications, e.g., rubber outsoles for footwear, due to some suitable properties, including good abrasion resistance and flexibility, white color, antimicrobial properties and attenuation of ultraviolet light (UV protection) connected with the presence of titanium dioxide particles. The further investigations (in the terms of specific industrial standards) should be performed before the application of this kind of materials.

\section{Compliance with ethical standards}

Conflict of interest The authors declare that they have no conflict of interest.

Open Access This article is distributed under the terms of the Creative Commons Attribution 4.0 International License (http://creativecommons.org/licenses/by/4.0/), which permits unrestricted use, distribution, and reproduction in any medium, provided you give appropriate credit to the original author(s) and the source, provide a link to the Creative Commons license, and indicate if changes were made.

\section{References}

1. Zhong B, Jia Z, Luo Y, Jia D (2015) A method to improve the mechanical performance of styrene-butadiene rubber via vulcanization accelerator modified silica. Compos Sci Technol 117:46-53

2. Le HH, Sriharish MN, Henning S, Klehm J, Menzel M, Frank W, Wießner S, Das A, Stöckelhuber KW, Heinrich G, Radusch HJ (2014) Dispersion and distribution of carbon nanotubes in ternary rubber blends. Compos Sci Technol 90:180-186

3. Hosseini SM, Razzaghi-Kashani M (2014) Vulcanization kinetics of nano-silica filled styrene butadiene rubber. Polymer 55:6426-6434

4. Tangudom P, Thongsang S, Sombatsompop N (2014) Cure and mechanical properties and abrasive wear behavior of natural rubber, styrene-butadiene rubber and their blends reinforced with silica hybrid fillers. Mater Des 53:856-864

5. Bellucci FS, Lobato de Almeida FC, Lima Nobre MA, Rodríguez-Péreze MA, Paschoalinia AT, Job AE (2016) Magnetic properties of vulcanized natural rubber nanocomposites as a function of the concentration, size and shape of the magnetic fillers. Compos Part B-Eng 85:196-206

6. Ali Shah A, Hasan F, Shah Z, Kanwal N, Zeb S (2013) Biodegradation of natural and synthetic rubbers: a review. Int Biodeter Biodegr 83:145-157

7. Ozbay S, Erbil HY (2015) Superhydrophobic and oleophobic surfaces obtained by graft copolymerization of perfluoroalkyl ethyl acrylate onto SBR rubber. Colloids Surf A 481:537-546

8. Seentrakoon B, Junhasavasdikul B, Chavasiri W (2013) Enhanced UV-protection and antibacterial properties of natural rubber/rutile- $\mathrm{TiO}_{2}$ nanocomposites. Polym Degrad Stabil 98:566-578

9. Ismail M, Abd El Ghaffar M, Shaffei K, Mohamed N (1999) Some novel polyamines as antioxidants for SBR vulcanizates. Polym Degrad Stabil 63:377-383

10. Erdem N, Erdogan UH, Cireli AA, Onar N (2010) Structural and ultraviolet-protective properties of nano- $\mathrm{TiO}_{2}$-doped polypropylene filaments. J Appl Polym Sci 115:152-157

11. Hayeemasae N, Rathnayake WGIU, Ismail H (2015) Nanosized $\mathrm{TiO}_{2}$-reinforced natural rubber composites prepared by latex compounding method. J Vinyl Addit Technol. doi:10.1002/ vnl.21497

12. Nabil H, Ismail H, Rashid AA (2012) Effects of partial replacement of commercial fillers by recycled poly(ethylene terephthalate) powder on the properties of natural rubber composites. $\mathbf{J}$ Vinyl AdditTechnol 18:139-146

13. Prasertsri S, Rattanasom N (2011) Mechanical and damping properties of silica/natural rubber composites prepared from latex system. Polym Test 30:515-526

14. Li Y, Han B, Liu L, Zhang F, Zhang L, Wen S, Lu Y, Yang H, Shen J (2013) Surface modification of silica by two-step method and properties of solution styrene butadiene rubber (SSBR) nanocomposites filled with modified silica. Compos Sci Technol 88:69-75 
15. Zhong B, Jia Z, Hu D, Luo Y, Jia D (2015) Reinforcement and reinforcing mechanism of styrene-butadiene rubber by antioxidant-modified silica. Compos Part A-Appl S 78:303-310

16. Cao X, Xu C, Liu Y, Chen Y (2013) Preparation and properties of carboxylated styrene-butadiene rubber/cellulose nanocrystals composites. Carbohydr Polym 92:69-76

17. Nasu A, Otsubo Y (2007) Rheology and UV-protecting properties of complex suspensions of titanium dioxides and zinc oxides. J Colloid Interf Sci 310:617-623

18. Jin M, Zhang X, Emeline AV, Numata T, Murakami T, Fujishima A (2008) Surface modification of natural rubber by $\mathrm{TiO}_{2}$ film. Surf Coat Tech 202:1364-1370

19. Zhang Q, Tian M, Wu Y, Lin G, Zhang L (2004) Effect of particle size on the properties of $\mathrm{Mg}(\mathrm{OH})_{2}$-filled rubber composites. J Appl Polym Sci 94:2341-2346

20. Rathnayake WGIU, Ismail H, Baharin A, Darsanasiri AGND, Rajapakse S (2012) Synthesis and characterization of nano silver based natural rubber latex foam for imparting antibacterial and anti-fungal properties. Polym Test 31:586-592

21. Zhou Y, Fan M, Chen L, Zhuang J (2015) Lignocellulosic fibre mediated rubber composites: an overview. Compos Part B-Eng 76:180-191

22. Ahmed K, Nizami SS, Raza NZ, Habib F (2013) The effect of silica on the properties of marble sludge filled hybrid natural rubber composites. J King Saud Univ Sci 25:331-339

23. Ahmed K, Nizami SS, Riza NZ (2014) Reinforcement of natural rubber hybrid composites based on marble sludge/Silica and marble sludge/rice husk derived silica. J Adv Res 5:165-173

24. Jong L (2015) Influence of protein hydrolysis on the mechanical properties of natural rubber composites reinforced with soy protein particles. Ind Crop Prod 65:102-109

25. Ochigbo SS, Luyt AS (2012) Mechanical and morphological properties of films based on ultrasound treated titanium dioxide dispersion/natural rubber latex. Int J Compos Mater 1:7-13

26. Kikuchi Y, Sunada K, Iyoda T, Hashimoto K, Fujishima A (1997) Photocatalytic bactericidal effect of $\mathrm{TiO}_{2}$ thin films: dynamic view of the active oxygen species responsible for the effect. J Photochem Photobiol A106:51-56

27. Meera AP, Said S, Grohens Y, Luty AS, Thomas S (2009) Tensile stress relaxation studies of $\mathrm{TiO}_{2}$ and nanosilica filled natural rubber composites. Ind Eng Chem Res 48:3410-3416. doi:10.1021/ ie801494s

28. Fu SY, Feng XQ, Lauke B, Mai YW (2008) Effects of particle size, particle/matrix interface adhesion and particle loading on mechanical properties of particulate-polymer composites. Compos Part B-Eng 39:933-961

29. Wang Z, Lu Y, Liu J, Dang Z, Zhang L, Wang W (2011) Preparation of nano-zinc oxide/EPDM composites with both good thermal conductivity and mechanical properties. J Appl Polym Sci 119:1144-1155

30. Das A, Stöckelhuber KW, Jurk R, Saphiannikova M, Fritzsche J, Lorenz H, Klüppel M, Heinrich G (2008) Modified and unmodified multiwalled carbon nanotubes in high performance solution-styrene-butadiene and butadiene rubber blends. Polymer 49:5276-5283

31. Ahmed K, Nizami SS, Raza NZ, Mahmood K (2012) Mechanical, swelling, and thermal aging properties of marble sludge-natural rubber composites. Int J Ind Chem 3:1-12

32. Datta J, Włoch M (2016) Preparation, morphology and properties of natural rubber composites filled with untreated short jute fibres. Polym Bull. doi:10.1007/s00289-016-1744-x

33. Manaila E, Stelescu MD, Doroftei F (2015) Polymeric composites based on natural rubber and hemp fibers. Iran Polym $\mathrm{J}$ 24:135-148

34. Delor F, Barrois-Oudin N, Duteurtre X, Cardinet C, Lemaire J, Lacoste J (1998) Oxidation of rubbers analysed by HATR/IR spectroscopy. Polym Degrad Stabil 62:395-401

35. Dhandapani S, Nayak SK, Mohanty S (2015) Compatibility effect of titanium dioxide nanofiber on reinforced biobasednanocomposites: thermal, mechanical, and morphology characterization. J Vinyl Addit Technol. doi:10.1002/vnl.21475

36. Sikong L, Masae M, Kooptarnond K, Taweepreda W, Saito F (2012) Improvement of hydrophilic property of rubber dipping former surface with $\mathrm{Ni} / \mathrm{B} / \mathrm{TiO}_{2}$ nano-composite film. Appl Surf Sci 258:4436-4443. doi:10.1016/j.apsusc.2012.01.002

37. Poompradub S, Ikeda Y, Kokubo Y, Shiono T (2008) Cuttlebone as reinforcing filler for natural rubber. Eur Polym $\mathrm{J}$ 44:4157-4164

38. Esthappan SK, Kuttappan SK, Joseph R (2012) Effect of titanium dioxide on the thermal ageing of polypropylene.Polym Degrad Stabil 97:615-620

39. Pinto D, Bernardo L, Amaro A, Lopes S (2015) Mechanical properties of epoxy nanocomposites using titanium dioxide as reinforcement-a review. Constr Build Mater 95:506-524

40. Hanemann T, Szabó DV (2010) Polymer-nanoparticle composites: from synthesis to modern applications. Materials 3:3468-3517

41. Pukánszky B (1990) Influence of interface interaction on the ultimate tensile properties of polymer composites. Composites 21:255-262

42. Leong YW, AbuBakar MB, Mohd Ishak ZA, Ariffin A, Pukanszky B (2004) Comparison of the mechanical properties and interfacial interactions between talc, kaolin, and calcium carbonate filled polypropylene composites. J Appl Polym Sci 91:3315-3326

43. Nath DCD, Bandyopadhyay S, Yu A, Zeng Q, Das T, Blackburn D, White C (2009) Structure-property interface correlation of fly ash-isotactic polypropylene composites. J Mater Sci 44:6078-6089

44. Kim W, Argento A, Flanigan C, Mielewski DF (2015) Effects of soy-based oils on the tensile behavior of EPDM rubber. Polym Test 46:33-40

45. Esthappan SK, Kuttappan SK, Joseph R (2012) Thermal and mechanical properties of polypropylene/titanium dioxide nanocomposite fibers. Mater Des 37:537-542 